\title{
A RELAÇÃO ENTRE A COMPETÊNCIA INFORMACIONAL E A ESTRUTURAÇÃO DA AULA DE QUÍMICA NOS PROFESSORES DE SERRA TALHADA - PE
}

\author{
THIAGO ARAÚJO DA SILVEIRA*
}

\begin{abstract}
RESUMO
Pesquisa realizada com sete professores de Química da rede pública de ensino de Serra Talhada - PE, investiga a relação entre as competências informacionais e a estruturação da aula que eles apresentavam. Discute brevemente as concepções e padrões de competência informacional baseado nas determinações da Association of College and Research Libraries, com enfoque nas atividades didáticas pelos professores de Química do ensino básico. Utilizou-se o questionário para coleta de dados, elaborado a partir de concepções e padrões de competência informacionais pra professores com formação superior da ACRL (2000) e dos elementos estruturantes de uma aula (LIBÂNEO, 1994; CORDEIRO, 2007). Os resultados mostram que os professores de Química questionados apresentam dificuldades em formular objetivos gerais e específicos para aula, em organizar a informação, em selecionar os recursos a partir das fontes consultadas; além de forte apego ao livro didático como fonte de informação. Conclui que a competência informacional do professor de Química de Serra Talhada necessita ser mais bem trabalhada e que a relação entre muitas dessas habilidades não se dão de forma coerente.
\end{abstract}

PALAVRAS-CHAVE: Competência informacional. Didática. Ensino de Química.

\section{ABSTRACT \\ THE RELATIONSHIP BETWEEN INFORMATION LITERACY AND THE STRUCTURING OF CHEMISTRY CLASSES IN TEACHERS FROM SERRA TALHADA - PE}

Research conducted with seven chemistry teachers from Serra Talhada PE educational public network, which investigates the relationship between the informational skills and the class structure they presented. It briefly discusses the conceptions and patterns of informational competence based on the determinations of the Association of College and Research Libraries, focusing on the didactic activities by the teachers of Basic Chemistry. The questionnaire was used to collect data, based on concepts and standards of informational competence for teachers with a higher education in ACRL (2000) and the structuring elements of a class (LIBÈNEO, 1994; CORDEIRO, 2007). The results show that the teachers of Chemistry questioned present difficulties in formulating general and

Professor Assistente da Universidade Federal Rural de Pernambuco - Serra Talhada. Doutorando no Ensino de Ciências pela Universidade Federal Rural de Pernambuco.tgsaraujo@gmail.com 
specific objectives for class, in organizing the information, in selecting the resources from the sources consulted; As well as a strong attachment to the textbook as a source of information. It concludes that the informational competence of the professor of Chemistry of Serra Talhada needs to be better worked and that the relation between many of these abilities do not occur in a coherent way.

KEYWORDS: Information Literacy. Didacticism. Chemistry Teaching.

\section{INTRODUÇÃO}

A competência informacional é um tema em amplo estágio de desenvolvimento da área de Biblioteconomia e Ciência da Informação. O assunto vem ganhando espaço considerável nas pesquisas científicas das áreas, por discutir as maneiras como os usuários dos sistemas de informação buscam, acessam, selecionam organizam e aplicam as informações (SANTOS, 2011; CAMPELLO, 2003).

Para o professor de Química, possuir habilidades na lida com a informação é essencial, pois, como profissional e mediador da informação, ele precisa saber articular componentes didáticos diretamente relacionados com a competência informacional (LIBÂNEO, 1994; CHOO, 2003).

A American Library Association (ALA) descreve a pessoa competente em informação da seguinte forma:

para ser competente em informação a pessoa deve ser capaz de reconhecer quando precisa de informação e possuir habilidade para localizar, avaliar e usar efetivamente a informação. Para produzir esse tipo de cidadania é necessário que escolas e faculdades compreendam o conceito de competência informacional e o integrem em seus programas de ensino e que desempenhem um papel de liderança preparando indivíduos e instituições para aproveitarem as oportunidades inerentes à sociedade da informação. Em última análise, pessoas que têm competência informacional são aquelas que aprenderam a aprender. Essas pessoas sabem como aprender porque sabem como a informação está organizada, como encontrar informação e como usar informação, de tal forma que outros possam aprender com elas (ALA, 1989).

O papel educativo da competência informacional historicamente foi atribuído ao bibliotecário, mas, para Campelo (2003) e Gasque (2012), essa mudança de paradigma é responsabilidade não somente desses profissionais, mas também do professor que trabalha com a informação em várias instâncias do seu trabalho didático e exerce grande influência na proliferação de 
fontes de informações e no processo de transformação das informações em conhecimento.

Sendo assim, essa pesquisa procura investigar as competências informacionais e as habilidades de estruturação de aulas apresentadas pelos professores de Química na cidade de Serra Talhada, utilizando um instrumento criado por nós, que relaciona essas duas questões aplicadas ao Ensino de Química.

Os dados coletados com o envio de um questionário on-line para sete professores de rede pública estadual no município de Serra Talhada - PE - permitiram relacionar as competências informacionais e a Didática dos professores de Química e discutir as suas influências no processo de ensino e aprendizagem da disciplina.

\section{COMPETÊNCIA INFORMACIONAL E O ENSINO DE QUÍMICA}

O termo competência informacional foi utilizado pela primeira vez nos Estados Unidos, na década de 1970, com o objetivo de designar as habilidades relacionadas com o uso da informação eletrônica. Para Dudziak (2003) apud Campello (2003), essa restrição colocada ao uso da informação somente nos meios digitais deveria ser superada, pois qualquer pessoa deveria ser capaz de explorar os diversos tipos de literacy ${ }^{1}$ que surgiram na última década, manejando-as com desenvoltura e desembaraço.

No inglês, a expressão information literacy foi utilizada pela primeira ver por Paul G. Zurkowski, e, no Brasil, esse termo foi traduzido para o português de diversas formas, entre elas, estão "alfabetização informacional", "letramento informacional", "habilidades informacionais" e "competência informacional", quase sempre tratando um grupo de ideias análogas. (GASQUE, 2012).

Neste trabalho, utilizaremos a concepção de competência informacional, defendida por Gasque (2012), Campello (2003) e Dudziak (2001), cujo termo significa a desenvoltura na formulação de questões, na avaliação da informação conforme sua pertinência, na sua organização e na sua aplicação para a resolução de questões originais.

Para nossa conversa, é importante questionar: "Por que a competência informacional é tão importante para os sujeitos?", "Por

\footnotetext{
${ }^{1}$ Literacy deve ser entendida como sinônimo de letramento. E o conceito de letramento informacional envolve a convivência com as diferentes manifestações informacionais imbricadas com suas práticas sociais. É dizer, estar letrado informacionalmente implica não somente decodificar a informação apresentada, mas saber selecioná-la, manejá-la, produzi-la e compartilhá-la, observando um contexto específico.
} 
que ela é tão importante para os professores de Química?".

Kuhlthau (1999) fala que o foco do trabalho com competência informacional, principalmente no campo da Ciência da Informação, é favorecer o processo de aprender a aprender, além de ensinar os sujeitos a buscar e usar a informação para produzir seu conhecimento. Esse enfoque ganha uma tônica ainda mais acentuada na chamada "Sociedade da Informação", na qual educar crianças e jovens é um desafio maior para a escola e para os profissionais que vivem e aprendem num contexto rico em informação.

Para o professor e, particularmente, para o professor de Química, a competência informacional ocupa uma necessidade de formação ainda mais relevante, observando as habilidades que deve possuir para realizar suas ações didáticas. Quando se considera o papel do professor de Química, Bougnoux (1994) o classifica como um mediador, que é o homem do meio, aquele que intermedeia duas extremidades: os conteúdos científicos e a aprendizagem dos estudantes.

Já para Lévy (1993), o professor de Química pode ser interpretado como interface, que traz a articulação, interpretação, tradução, amplificação, filtração, conservação e/ou transmissão entre dois espaços: o conhecimento socialmente construído e o aluno que aprende.

Sendo assim, a necessidade de competências informacionais para o professor ganha um papel de destaque, uma vez que ele realiza as adaptações, filtros e/ou articulações entre o conhecimento químico e o conteúdo que será disponibilizado e aprendido em sala de aula. É dizer, o professor que não sabe buscar, selecionar, organizar e compartilhar a informação de forma precisa reduzirá as condições de produção de conhecimento (CAMPELLO, 2003; 2006).

O professor de Química todos os dias enfrenta desafios advindos de transformações políticas, curriculares, sociais e culturais. Ser competente no manejo da informação é agora uma condição para desempenhar bem as suas atividades. Para Gasque (2012, p. 113):

É também necessário que exista a preocupação em relacionar o trabalho de apropriação de saberes com o de construção das competências docentes básicas e que têm relação direta com essa prática. De fato, muito frequentemente se exige que o docente seja didaticamente criativo, enquanto sua formação básica e continuada em serviço é pouco inovadora, às vezes mesmo anacrônica.

Para Campello (2003) e Gasque (2012), o professor deve ser 
competente com a informação para executar bem suas atividades didáticas, saber projetar metas de aprendizado para seus estudantes e saber orientar as atividades que solicita dos educandos.

As atividades que envolvem a estruturação da aula no Ensino de Química que se constituem de componentes sistematicamente articulados (objetivos, conteúdos, métodos e condições) são muito dependentes da competência que o professor possui para buscar e usar a informação. Ou seja, há uma relação direta entre os processos didáticos e a competência informacional do professor. (LIBÂNEO, 1994; CHOO, 2003).

Para a International Federation of Library Associations and Institutions - IFLA (2002), é papel do professor "atuar no sentido proativo, para promover e facilitar 0 acesso responsável à informação de qualidade em rede a todos os seus usuários, inclusive as crianças e os jovens." (p. 5).

\section{PADRÕES DE COMPETÊNCIA INFORMACIONAL}

No nosso estudo, foram utilizados os Padrões estabelecidos pela Association of College and Research Libraries (ACRL, 2000). Esses padrões foram escolhidos por serem elaborados para implementação no Ensino Superior.

A ACRL é a instituição autora do documento Padrões de Competência Internacional para o Ensino Superior (Information Literacy Competency Standarts for Higher Education), que visa estimular a formação de indivíduos mais capazes de atuar em sistemas de abundantes escolhas informacionais e em ambientes complexos e não lineares.

Os parâmetros estabelecidos pela ACRL são constituídos de cinco padrões distribuídos em 22 indicadores de desempenho e uma lista de resultados esperados pelos estudantes do ensino superior.

Esses padrões foram escolhidos em virtude dos resultados que se esperam do professor de Química em suas atividades, da sua profissionalização e da capacidade de enfrentamento de mudanças que deve possuir.

Assim, o quadro 1 apresenta esses padrões (ACRL, 2000):

QUADRO 1 - Padrões de Competência informacional Internacional para o Ensino Superior

\begin{tabular}{l|l}
\hline Padrão & Descrição \\
\hline Padrão 1 & $\begin{array}{l}\text { O indivíduo competente em informação determina a natureza e o nível } \\
\text { de sua necessidade de informação. }\end{array}$ \\
\hline
\end{tabular}




\begin{tabular}{l|l}
\hline Padrão 2 & $\begin{array}{l}\text { O indivíduo competente em informação acessa a informação } \\
\text { necessária eficaz e eficientemente }\end{array}$ \\
\hline Padrão 3 & $\begin{array}{l}\text { O indivíduo competente em informação avalia a informação e suas } \\
\text { fontes de forma crítica e incorpora a informação selecionada a seus } \\
\text { conhecimentos básicos e a seu sistema de valores. }\end{array}$ \\
\hline Padrão 4 & $\begin{array}{l}\text { O indivíduo competente em informação, individualmente ou na } \\
\text { qualidade de membro de um grupo, utiliza a informação eficazmente } \\
\text { para alcançar um propósito específico. }\end{array}$ \\
\hline Padrão 5 & $\begin{array}{l}\text { O indivíduo competente em informação compreende muitos problemas } \\
\text { e questões econômicas, legais e sociais que rodeiam o uso da } \\
\text { informação e acessa e utiliza a informação de forma ética e legal. }\end{array}$ \\
\hline
\end{tabular}

O Padrão 1, segundo Sullivan (2006), refere-se à habilidade de se reconhecer a necessidade de informação e as necessidades de se identificar os variados tipos e formatos das fontes de informação.

O segundo padrão, de acordo com Mata (2009), aborda "uma significante variedade de atividades relacionadas à pesquisa, incluindo seleção da metodologia, técnicas de pesquisa e recuperação e análise da informação" (p. 48).

Santos (2011) revela que o padrão 3 trabalha a capacidade de aplicação de critérios de avaliação de uma informação, a verificação de sua confiabilidade, validade, precisão, autoridade e atualização, sabendo extrair suas ideias principais e construir conhecimento.

A autora ainda explica o padrão 4 (p. 102):

Para ser considerado competente neste padrão o indivíduo deve ser capaz de aplicar a nova informação adquirida no planejamento e criação de um novo produto ou desempenho particular, articular e integrar conhecimentos e habilidades anteriores e novos, manipular textos, imagens e dados em qualquer suporte a fim de apoiar seus propósitos almejados.

E, por fim, o Padrão 5, busca que o estudante saiba reconhecer as implicações sociais inerentes aos sistemas e à produção da informação.

Parece bastante conveniente utilizar esse padrão para avaliação da competência informacional do Professor de Química da cidade de Serra Talhada, uma vez que deverá ser utilizada durante todo o seu trabalho e lhe dará condições de conduzi-lo coerentemente dentro de uma aplicação didática.

\section{METODOLOGIA}


Este trabalho emprega métodos e técnicas típicos de uma abordagem qualitativa, que possui características próprias; hoje se constitui como um dos métodos mais utilizados para realização de pesquisas em áreas especificamente humanas, tais como a Psicologia, a Educação e a Sociologia (NEVES, 1996).

Para a autora, uma pesquisa que se situa nessa abordagem deve apresentar algumas características: ter o ambiente natural como fonte de dados e o pesquisador como instrumento fundamental; possuir caráter descritivo; mostrar como as pessoas dão significados às coisas e/ou à sua vida no contexto determinado de pesquisa e ter enfoque indutivo.

Neste trabalho, foi realizado um estudo de caso, com a utilização de um questionário, elaborado a partir dos padrões internacionais de Competência Informacional para o Ensino Superior propostos pela ACRL (2000), e das recomendações estruturantes de elaboração de aula definidas por Libâneo (1994) e Cordeiro (2007).

A amostra do estudo de caso foi de sete professores de Química da rede pública cidade Serra Talhada, cidade do Sertão do Pajeú, em Pernambuco, que responderam ao questionário que receberam por e-mail em formato digital. A escolha desta forma de questionário foi devida às possibilidades de armazenamento das respostas na nuvem ${ }^{2}$ para posterior uso e tabulação dos dados obtidos.

O questionário possuía treze questões que contemplavam os cinco padrões de competências da ACRL (2000), adaptados para os elementos estruturantes da aula de Química (LIBÂNEO, 1994; CORDEIRO, 2007).

A seguir, apresentamos as perguntas do questionário, sua tipologia e a relação feita entre os resultados de padrões de competências esperados e os elementos didáticos avaliados.

QUADRO 2 - Padrões de competência x Elementos estruturantes da aula.

\begin{tabular}{c|c|c|c}
\hline Pergunta & $\begin{array}{c}\text { Tipo de } \\
\text { pergunta }\end{array}$ & $\begin{array}{c}\text { Padrão de } \\
\text { competência } \\
\text { esperada }\end{array}$ & $\begin{array}{c}\text { Elemento didático } \\
\text { avaliado }\end{array}$ \\
\hline
\end{tabular}

\footnotetext{
${ }^{2}$ Armazenamento em nuvem: refere-se ao uso e armazenamento de arquivos como textos, planilhas, apresentações etc., diretamente em servidores conectados à Internet. Esse serviço permite o acesso e a modificação desses arquivos em qualquer lugar, desde que se possua um dispositivo (smartphones, tablets ou computadores) conectado à rede.
} 


\begin{tabular}{|c|c|c|c|}
\hline $\begin{array}{c}\text { Formular } \\
\text { objetivos gerais } \\
\text { e específicos de } \\
\text { aula, com base } \\
\text { na necessidade } \\
\text { de informação } \\
\text { dos alunos. }\end{array}$ & $\begin{array}{c}\text { Escala de } \\
\text { classificação }\end{array}$ & $\begin{array}{l}\text { Padrão } 1 \text { - nesta } \\
\text { questão, o professor } \\
\text { deve ter em mente } \\
\text { as necessidades de } \\
\text { informações que } \\
\text { seus alunos devem } \\
\text { possuir, propondo } \\
\text { objetivos gerais e } \\
\text { específicos de aula } \\
\text { que sirvam como } \\
\text { meta de informação } \\
\text { para eles, e nortear } \\
\text { o seu posterior } \\
\text { trabalho de busca, } \\
\text { seleção e } \\
\text { organização da } \\
\text { informação. }\end{array}$ & $\begin{array}{c}\text { Elaboração de } \\
\text { Objetivos Gerais e } \\
\text { específicos. Para } \\
\text { Libâneo (1994), o } \\
\text { professor deve } \\
\text { conhecer os objetivos } \\
\text { vinculados não } \\
\text { somente ao } \\
\text { conhecimento científico } \\
\text { esperados dos } \\
\text { estudantes, mas } \\
\text { também sobre o papel } \\
\text { da escola na formação } \\
\text { de cidadãos ativos e } \\
\text { participantes da vida } \\
\text { social. }\end{array}$ \\
\hline $\begin{array}{c}\text { Identificar fontes } \\
\text { de informação } \\
\text { para a aula }\end{array}$ & $\begin{array}{l}\text { Escala de } \\
\text { classificação }\end{array}$ & $\begin{array}{c}\text { Padrão 1-a } \\
\text { questão avalia o } \\
\text { grau de dificuldade } \\
\text { do professor no } \\
\text { reconhecimento de } \\
\text { fontes informações } \\
\text { que serão } \\
\text { necessárias para o } \\
\text { preparo da aula. }\end{array}$ & $\begin{array}{c}\text { Identificação dos } \\
\text { conteúdos de ensino. } \\
\text { Para Libâneo (1994) e } \\
\text { Cordeiro (2007), a } \\
\text { identificação dos } \\
\text { conteúdos de ensino } \\
\text { permite que professor } \\
\text { e alunos façam uma } \\
\text { assimilação consciente } \\
\text { e sólida dos } \\
\text { conhecimentos da } \\
\text { aula, tornando-os mais } \\
\text { significativos. }\end{array}$ \\
\hline $\begin{array}{c}\text { Acessar fontes } \\
\text { de informação } \\
\text { para realização } \\
\text { da aula }\end{array}$ & $\begin{array}{l}\text { Escala de } \\
\text { classificação }\end{array}$ & $\begin{array}{l}\text { Padrão } 2-\text { a } \\
\text { pergunta analisa a } \\
\text { dificuldade do } \\
\text { professor no acesso } \\
\text { às informações para } \\
\text { realização da aula. }\end{array}$ & $\begin{array}{l}\text { Pesquisa no ensino. } \\
\text { Esse elemento didático } \\
\text { trata do domínio das } \\
\text { ferramentas de acesso } \\
\text { à informação que o } \\
\text { professor utiliza, bem } \\
\text { como a facilidade com } \\
\text { que ele lida com elas. }\end{array}$ \\
\hline $\begin{array}{c}\text { Selecionar o } \\
\text { corpo de } \\
\text { informações que } \\
\text { serão } \\
\text { trabalhadas em } \\
\text { sala de aula }\end{array}$ & $\begin{array}{c}\text { Escala de } \\
\text { classificação }\end{array}$ & $\begin{array}{c}\text { Padrão } 3 \text { - esse } \\
\text { padrão revela a } \\
\text { capacidade de } \\
\text { professor avaliar a } \\
\text { informação que será } \\
\text { apresentada na aula, } \\
\text { e, também, a sua } \\
\text { habilidade em filtrá- }\end{array}$ & $\begin{array}{c}\text { Seleção de conteúdos. } \\
\text { Para Libâneo (1994), } \\
\text { "a escolha dos } \\
\text { conteúdos é uma das } \\
\text { tarefas mais } \\
\text { importantes para o } \\
\text { professor" (p.142). } \\
\text { Nesse tópico, o nível }\end{array}$ \\
\hline
\end{tabular}

\footnotetext{
${ }^{3}$ As perguntas do tipo de classificação utilizaram a Escala Likert, que mede atitudes e comportamentos utilizando opções de resposta que variam de um extremo a outro. No nosso caso, a escala variou da seguinte maneira: o número 1 equivale a "muita dificuldade" e número 5 a "muita facilidade".
} 


\begin{tabular}{|c|c|c|c|}
\hline & & la. & $\begin{array}{l}\text { de dificuldade que o } \\
\text { professor apresenta } \\
\text { indicará diretamente } \\
\text { seus problemas em } \\
\text { fazer uma escolha } \\
\text { criteriosa dos } \\
\text { conteúdos que sejam } \\
\text { relevantes para a } \\
\text { participação dos } \\
\text { estudantes na vida } \\
\text { social. }\end{array}$ \\
\hline $\begin{array}{c}\text { Organizar a } \\
\text { informação para } \\
\text { aplicação em } \\
\text { aula }\end{array}$ & $\begin{array}{c}\text { Escala de } \\
\text { classificação }\end{array}$ & $\begin{array}{l}\text { Padrão } 3 \text { e } 4 \text { - essa } \\
\text { questão avalia o } \\
\text { grau de dificuldade } \\
\text { na organização da } \\
\text { informação para } \\
\text { aplicação na aula. }\end{array}$ & $\begin{array}{c}\text { Distribuição e } \\
\text { sistematização do } \\
\text { conhecimento. Na fala } \\
\text { de Libâneo (1994), } \\
\text { para o professor } \\
\text { organizar } \\
\text { coerentemente a } \\
\text { informação em sala, é } \\
\text { preciso que ele } \\
\text { conheça e compreenda } \\
\text { os aspectos } \\
\text { específicos dessa } \\
\text { informação, e saiba } \\
\text { apresentá-la de acordo } \\
\text { com seus níveis de } \\
\text { complexidade. }\end{array}$ \\
\hline $\begin{array}{l}\text { Escolher os } \\
\text { recursos } \\
\text { didáticos com } \\
\text { base nas } \\
\text { informações } \\
\text { selecionadas } \\
\text { para a aula }\end{array}$ & $\begin{array}{c}\text { Escala de } \\
\text { classificação }\end{array}$ & $\begin{array}{c}\text { Padrão } 3 \text { e Padrão } 4 \\
\text { - a questão revela o } \\
\text { grau de } \\
\text { entendimento do } \\
\text { professor acerca da } \\
\text { adequação entre } \\
\text { informação e } \\
\text { escolha de artefatos } \\
\text { que operacionalizem } \\
\text { o seu processo de } \\
\text { compartilhamento. }\end{array}$ & $\begin{array}{l}\text { Seleção de Recursos } \\
\text { Didáticos. Para Nuñéz } \\
\text { et al. (2014), a seleção } \\
\text { de recursos didáticos } \\
\text { deve buscar critérios } \\
\text { específicos para os } \\
\text { contextos didáticos em } \\
\text { que serão aplicados. } \\
\text { Da mesma forma, as } \\
\text { informações que serão } \\
\text { trabalhadas com os } \\
\text { recursos devem estar } \\
\text { adequadas para a } \\
\text { ação e explanação da } \\
\text { informação, evitando } \\
\text { desvios e erros } \\
\text { conceituais. }\end{array}$ \\
\hline $\begin{array}{c}\text { Marque as suas } \\
\text { ações ao } \\
\text { desenvolver o } \\
\text { planejamento }\end{array}$ & $\begin{array}{l}\text { Múltipla } \\
\text { escolha }{ }^{4}\end{array}$ & $\begin{array}{c}\text { Padrão } 3 \text { - Esta } \\
\text { questão avalia que } \\
\text { ações o professor de } \\
\text { química recorre na }\end{array}$ & $\begin{array}{c}\text { Preparação da aula. } \\
\text { Esse processo revela o } \\
\text { planejamento } \\
\text { sistemático das }\end{array}$ \\
\hline
\end{tabular}

\footnotetext{
${ }^{4}$ As questões do tipo múltipla escolha permitiam que o participante escolhesse uma ou mais alternativas daquelas que estavam disponíveis.
} 


\begin{tabular}{|c|c|c|c|}
\hline didático da aula: & & $\begin{array}{c}\text { elaboração da sua } \\
\text { aula. }\end{array}$ & $\begin{array}{c}\text { informações que serão } \\
\text { disponibilizadas, a } \\
\text { "dosagem da matéria", } \\
\text { bem como essas } \\
\text { diversas fontes } \\
\text { acabarão se tornando } \\
\text { um todo único com um } \\
\text { fim específico, no caso, } \\
\text { a aula. }\end{array}$ \\
\hline $\begin{array}{c}\text { Ao buscar } \\
\text { informações } \\
\text { para elaboração } \\
\text { da sua aula, } \\
\text { quais suas } \\
\text { ações mais } \\
\text { recorrentes: }\end{array}$ & Múltipla escolha & $\begin{array}{l}\text { Padrão } 3 \text { - Nesse } \\
\text { momento, são } \\
\text { investigadas as } \\
\text { ações do professor } \\
\text { no contato com o } \\
\text { conjunto de fontes } \\
\text { que teve acesso e } \\
\text { selecionou. }\end{array}$ & $\begin{array}{l}\text { Preparação da aula. } \\
\text { Essa questão tem por } \\
\text { objetivo verificar o } \\
\text { conjunto de ações do } \\
\text { professor que tornam o } \\
\text { conteúdo/informações } \\
\text { da aula um todo } \\
\text { significativo. }\end{array}$ \\
\hline $\begin{array}{c}\text { Durante o } \\
\text { desenvolviment } \\
\text { o da pesquisa } \\
\text { para a aula, } \\
\text { quais fontes } \\
\text { você considera } \\
\text { confiável para } \\
\text { uso: }\end{array}$ & Múltipla escolha & $\begin{array}{c}\text { Padrão } 3 \text { e } 4 \text { - a } \\
\text { questão avalia a } \\
\text { competência do } \\
\text { professor em avaliar } \\
\text { a confiabilidade das } \\
\text { fontes que utilizará } \\
\text { para um fim } \\
\text { específico. }\end{array}$ & $\begin{array}{c}\text { Cientificidade dos } \\
\text { conteúdos. A questão } \\
\text { avalia a capacidade do } \\
\text { professor em } \\
\text { selecionar os } \\
\text { conhecimentos que } \\
\text { representem } \\
\text { conhecimentos } \\
\text { devidamente validados } \\
\text { pela comunidade } \\
\text { científica. }\end{array}$ \\
\hline $\begin{array}{c}\text { Após selecionar } \\
\text { os documentos } \\
\text { e informações } \\
\text { relevantes para } \\
\text { aula, o que você } \\
\text { faz? }\end{array}$ & Múltipla escolha & $\begin{array}{c}\text { Padrão } 3 \text { e } 4 \text { - aqui, } \\
\text { o professor é } \\
\text { avaliado quanto à } \\
\text { sua capacidade de } \\
\text { criticar a informação } \\
\text { que está utilizando. }\end{array}$ & $\begin{array}{l}\text { Seleção dos } \\
\text { conteúdos. }\end{array}$ \\
\hline $\begin{array}{l}\text { De posse das } \\
\text { informações } \\
\text { para a aula, o } \\
\text { que você faz? }\end{array}$ & Múltipla escolha & $\begin{array}{l}\text { Padrão } 3 \text { e } 4 \text { - são } \\
\text { observadas as ações } \\
\text { de transformação da } \\
\text { informação para } \\
\text { realização da aula } \\
\text { pelo professor. }\end{array}$ & $\begin{array}{c}\text { Transposição didática } \\
\text { externa. Esse processo } \\
\text { pode ser entendido } \\
\text { como a transformação } \\
\text { do saber científico em } \\
\text { saber a ser ensinado. } \\
\text { (BRITO MENEZES, } \\
\text { 2006) }\end{array}$ \\
\hline $\begin{array}{l}\text { Quais recursos } \\
\text { você utiliza para } \\
\text { apresentar as } \\
\text { informações na } \\
\text { aula, justifique } \\
\text { suas escolhas: }\end{array}$ & $\begin{array}{l}\text { Múltipla escolha } \\
\text { e Dissertativa }\end{array}$ & $\begin{array}{c}\text { Padrão } 4 \text { - o objetivo } \\
\text { dessa questão é } \\
\text { verificar quais os } \\
\text { principais produtos } \\
\text { que os professores } \\
\text { transformam as } \\
\text { informações que } \\
\text { acessam para sua } \\
\text { aula. }\end{array}$ & $\begin{array}{l}\text { Utilização do Recurso } \\
\text { Didático. }\end{array}$ \\
\hline Você costuma & Múltipla escolha & Padrão 5 - & Compartilhamento do \\
\hline
\end{tabular}




\begin{tabular}{|c|c|c|c|}
\hline $\begin{array}{c}\text { fazer e } \\
\text { apresentar as } \\
\text { referências que } \\
\text { utiliza em aula, } \\
\text { por quê? }\end{array}$ & e Dissertativa & $\begin{array}{c}\text { verificação da } \\
\text { importância dada } \\
\text { para os aspectos } \\
\text { legais e sociais que } \\
\text { rodeiam o uso da } \\
\text { informação, tais } \\
\text { como citação e } \\
\text { disponibilização das } \\
\text { referências. }\end{array}$ & $\begin{array}{l}\text { conteúdo e } \\
\text { socialização do } \\
\text { conhecimento } \\
\text { científico. }\end{array}$ \\
\hline
\end{tabular}

Para a análise de dados, foi realizada a análise quantitativa, que foi comparada aos resultados propostos para os indicadores de desempenho dos padrões propostos pela ACRL (2000) e aos elementos estruturantes de uma aula proposto por Libâneo (1994) e Cordeiro (2007). Essa comparação, segundo Santos (2011), permite interpretar a compatibilidade de um indivíduo considerado competente em informação.

\section{RESULTADOS E DISCUSSÕES}

Para melhor organização dos dados, os resultados serão analisados na sua sequência de aplicação, e discutidos na sequência do texto.

A questão 1 buscou analisar grau de dificuldade em identificar as necessidades de informação que os professores projetam como meta para seus estudantes, e como elas se convertem em objetivos gerais e específicos de aula. Os resultados foram os seguintes

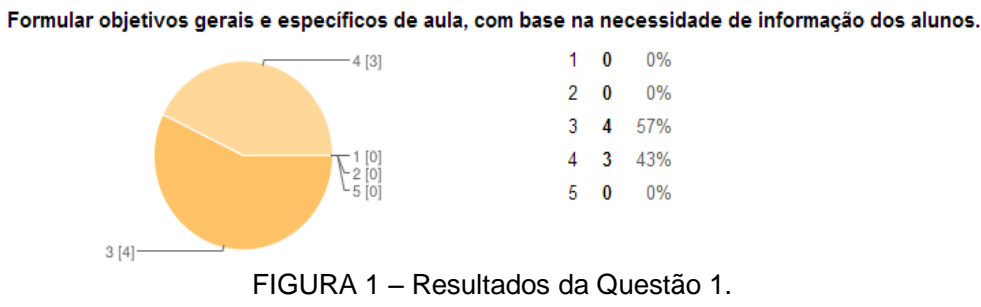

Os dados informam que a maioria dos professores $(57 \%$ relativos) apresenta nível de dificuldade 3 para formulação de objetivos para aula, com base na necessidade de informação dos estudantes. Outros professores apresentam nível de dificuldade 4 nesse tópico. Em suma, a maior parte dos professores de Química avaliados apresenta alguma dificuldade em delinear as 
necessidades de informação dos educandos e, a partir deles, elaborar objetivos gerais e específicos para a aula.

Para Libâneo (1994) e Maia, Sheibel e Urban (2009), a elaboração dos objetivos gerais e específicos é condicionante para a qualidade da formação dos estudantes, pois ela determinará quais habilidades e competências deverão ser desenvolvidas. $\mathrm{Na}$ formação em Química, a formulação adequada de objetivos fornecem diretrizes para a ação educativa como um todo, delineia os conteúdos conceituais, procedimentais e atitudinais relacionados à disciplina que os estudantes deverão adquirir e facilitam o processo avaliativo do aproveitamento do estudante e do trabalho docente.

$\mathrm{Na}$ questão 2, o professor indicou seu nível de dificuldade em reconhecer fontes de informações que utilizará na aula. Didaticamente falando, esse ponto trata da identificação dos conteúdos de ensino. Os dados obtidos foram:

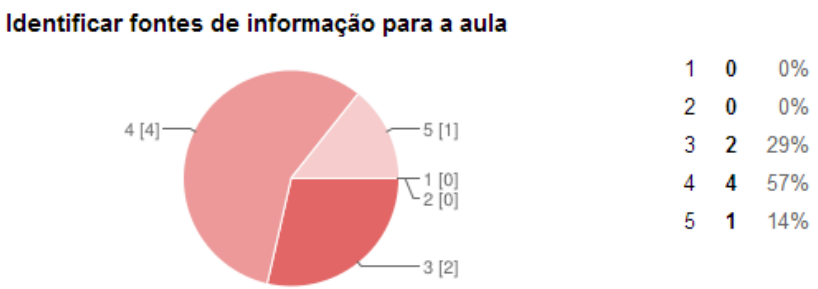

FIGURA 2 - Resultados da Questão 2.

A maioria dos professores (5 professores - 71\%) informa ter facilidade em identificar fontes de informação para aula, se somados os níveis 4 e 5 da escala. Esses dados permitem a discussão de que os professores de Química não apresentam dificuldades em identificar fontes de informação, porém Santos (2011), que também encontrou dados semelhantes em sua pesquisa, justifica que os resultados são frutos de uma superestimação que os respondentes têm a respeito de suas próprias habilidades com a informação, e que estes mesmos sujeitos, quando obrigados a demonstrar seus conhecimentos, nem sempre verificam essa superestimação. Acredita-se que a realização de mais estudos e pesquisas com uma amostragem maior de professores de Química, que contemplem a demonstração dessas habilidades, possa fornecer resultados mais categóricos.

$\mathrm{Na}$ questão 3, os professores respondentes informaram ter facilidade ou muita facilidade em acessar a informação para a aula: 


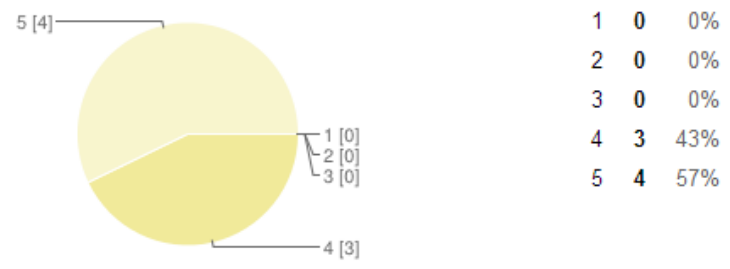

FIGURA 3 - Resultados da Questão 3.

O nível de facilidade no acesso às fontes de informação é interpretado por Santos (2011) como uma alta habilidade em selecionar o método ou sistema de informações mais apropriados para acessar a informação.

A próxima questão trata da seleção que o professor faz das informações obtidas nas fontes, com os seguintes resultados:

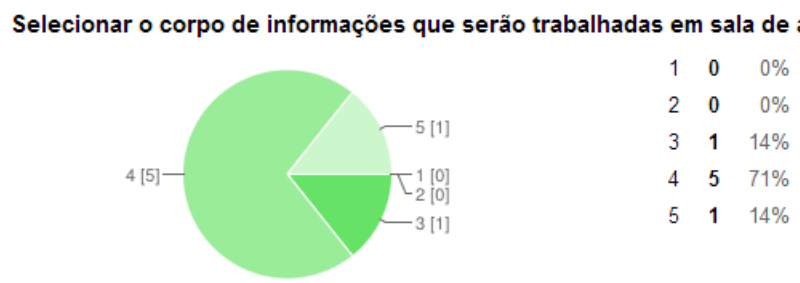

FIGURA 4 - Resultados da Questão 4.

Os resultados apontam que os professores de Química não encontram dificuldades na seleção do conteúdo a ser trabalhado em sala de aula (85\% dos professores responderam nível 4 e 5). Essa competência diz que o professor apresenta destreza na seleção do que realmente atende à necessidade de informação, ou seja, o professor sabe delimitar qual o assunto que deve estar presente na aula, além de saber recuperar aquelas informações perdidas no processo de acesso e reconhecimento da informação.

Entretanto, esses resultados podem ser inconsistentes quando comparados aos da questão 1. Para Libâneo (1994), a relação entre objetivos da aula e seleção de conteúdos é um processo interligado, pois deve haver conjugação entre o que se espera dos estudantes e o que deve ser apresentado para eles em termos de conteúdo.

$\mathrm{Na}$ questão 5, o professor é avaliado em termos de organização da informação. 


\section{Organizar a informação para aplicação em aula}
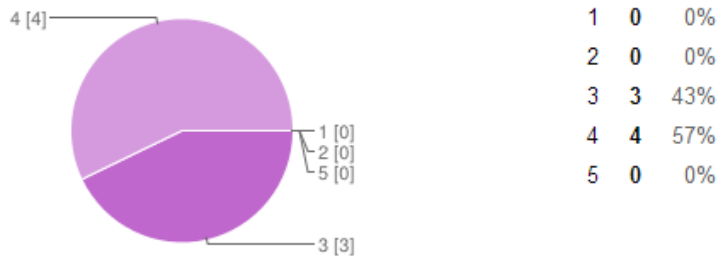

FIGURA 5 - Resultados da Questão 5.

Cinquenta e sete por cento dos pesquisados dizem não apresentar dificuldades em organizar as informações coletadas nas fontes, enquanto $43 \%$ restantes apresentam nem facilidade nem dificuldade nessa atividade. Para Cordeiro (2007), o processo de organização da informação é importante para o ensino, pois facilita o desencadeamento das atividades, e também para o aprendizado, pois os conteúdos precisam ser apresentados com uma coerência interna e lógica, que envolve a complexidade desse processo de organização.

A sexta questão trata da seleção dos recursos didáticos em consonância com as informações selecionadas para aula:

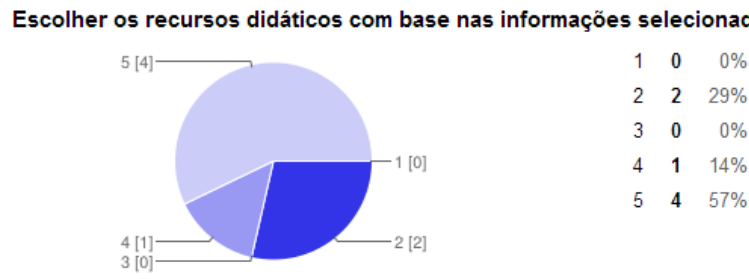

FIGURA 6 - Resultados da Questão 6.

Neste tópico, a maioria dos professores afirma ter muita facilidade na seleção dos recursos didáticos, apenas um revela ter facilidade, e dois professores informam ter dificuldades em fazer essa escolha. É importante destacar a importância dessa questão para o processo instrucional no Ensino de Química. Os recursos didáticos são auxiliadores da aprendizagem, pois permitem a ligação entre a teoria e a prática, e facilitam a construção de modelos mentais e/ou explicativos dos fenômenos naturais. Embora o número de professores que apresentem essa dificuldades seja de $29 \%$, esses dados merecem ser apreciados.

A sétima questão avalia as ações que o professor realiza a partir de uma necessidade de informação. Os resultados estão no quadro a seguir: 
QUADRO 3 - Resultados da Questão 7

\begin{tabular}{l|c}
\hline Pontos avaliados & Frequência \\
\hline Discute o assunto com colegas e professores & 5 \\
\hline Utiliza a biblioteca e seus serviços & 2 \\
\hline $\begin{array}{l}\text { Consulta fontes de informações especializadas (periódicos, base de } \\
\text { dados, Scielo, Google acadêmico, etc.) }\end{array}$ & 3 \\
\hline Consulta livros didáticos do Ensino Médio & 7 \\
\hline Consulta livros didáticos do Ensino Superior & 2 \\
\hline Identifica conceitos chave e termos relacionados ao tema de pesquisa & 3 \\
\hline
\end{tabular}

Esses resultados apontam uma tendência do professor de Química consultar o livro didático do Ensino Médio como fonte de informação para aula (todos os professores), e os colegas e professores (5 professores). O que chama a atenção é o baixo índice de pesquisados que vão à biblioteca como ação recorrente de planejamento (com apenas 2 professores). Esse fato elucida a tendência do professor de Química participante em não procurar ajuda especializada para acessar a informação. Outro dado que ressalta aos olhos é a baixa consulta aos livros didáticos do Ensino Superior. Essa situação pode representar uma dificuldade de o professor transpor didaticamente as informações que este tipo de recurso apresenta, geralmente mais densa e de nível elevado, para um saber que possa ser ensinado. Consultas a fontes de informações especializadas e identificação de conceitos chaves e termos de pesquisa apareceu com 3 citações pelos professores, um nível também baixo, considerando que a Química é uma ciência com alto nível de especificidade conceitual.

A oitava questão avalia questões mais específicas de busca às fontes de informação, são elas:

QUADRO 4 - Resultados da Questão 8.

\begin{tabular}{l|c}
\hline Pontos avaliados & Frequência \\
\hline Pesquisar em um buscador como o Google como ponto de partida & 5 \\
\hline Ir à biblioteca e tentar localizar tudo disponível sobre o tema da aula & 1 \\
\hline $\begin{array}{l}\text { Pesquisar em diversas fontes de informação e em diferentes } \\
\text { formatos (escrita, áudio, audiovisual, etc.) }\end{array}$ & 7 \\
\hline Construir estratégias de buscas gerais para fazer pesquisa. & 2 \\
\hline Outros & 0 \\
\hline
\end{tabular}

Nesse ponto, os professores de Química, em sua totalidade, informaram pesquisar em diversas fontes de informação e em diferentes formatos. De acordo com ACRL (2000), o indivíduo competente informacionalmente utiliza-se de uma gama de métodos para buscar a informação de que necessita. Essa navegação entre 
diferentes tipos de formatos pode formar o professor a também apresentar essa informação aos seus alunos de forma variada (LIBÂNEO, 1994). Outro dado importante foi a grande quantidade de pesquisados que utilizam motores de busca de informação na internet como ponto de partida para sua pesquisa, em detrimento daqueles que usam a biblioteca para localizar a informação. O item "construir estratégias de buscas gerais para fazer pesquisa" foi assinalado por dois professores, esse número informa que os professores de Química buscam resultados mais específicos em suas pesquisas.

A questão seguinte quer avaliar quais fontes de informação são consideradas confiáveis pelo professor de Química, e o resultado foi:

\section{QUADRO 5 - Resultados da Questão 9.}

\begin{tabular}{|l|c|}
\hline Ponto avaliado & Frequência \\
\hline Fontes recomendadas por professores/colegas de área & 5 \\
\hline Bibliografia indicada no final de livros e artigos. & 5 \\
\hline Fontes da internet & 3 \\
\hline Fontes de base de dados & 0 \\
\hline Anais de eventos ou publicações da área. & 2 \\
\hline Artigos de revisão & 1 \\
\hline Livros didáticos & 7 \\
\hline Livros paradidáticos & 2 \\
\hline Outros & 0 \\
\hline
\end{tabular}

Aqui o livro didático aparece como fonte mais confiável de pesquisa para os professores avaliados. Para Romanatto (1987), o problema desse resultado não se encontra no uso dessa fonte de informação, mas da dependência que o professor possa revelar no seu uso, para ele, "muitos fatores têm contribuído para que o livro didático tenha esse papel de protagonista na sala de aula. ... um livro que promete tudo pronto, tudo detalhado, (...) é uma atração irresistível" (p. 85). "A bibliografia indicada no final de livros e artigos" e "Fontes recomendadas por professores/colegas de área" apareceram em segundo lugar na confiança dos professores, revelando a importância dada à referenciação feita pelos autores de livros e artigos, aos colegas de área na pesquisa para a aula. Fontes da internet são consideradas confiáveis para 3 professores, dado que estampam a falta de confiabilidade da maioria dos professores nessa fonte. "Livros paradidáticos" e "Anais de eventos ou publicações da área" aparecem em seguida e informações de base de dados não foi citada por nenhum professor. 
A questão de número 10 verifica as ações transformadoras do professor, sua capacidade de criticar a informação que está utilizando.

QUADRO 6 - Resultados da Questão 10.

\begin{tabular}{l|c}
\hline Ponto avaliado & Frequência \\
\hline Lê os textos e seleciona as ideias principais & 7 \\
\hline $\begin{array}{l}\text { Lê apenas o resumo ou as partes principais dos documentos para } \\
\text { saber se aproveitaria. }\end{array}$ & 1 \\
\hline Constrói resumos ou esquemas com suas próprias palavras & 5 \\
\hline Identifica diferentes abordagens que cada autor dá ao tema. & 3 \\
\hline Outros & 0 \\
\hline
\end{tabular}

Os resultados indicam que a maior parte dos professores de Química realiza o conjunto de ações, "Lê os textos e seleciona as ideias principais" e "Constrói resumos ou esquemas com suas próprias palavras" como propostas recorrentes de transformação da informação que buscaram. De acordo com a ACRL (2000), o indivíduo com competência informacional deve extrapolar a leitura do texto e seleção das ideias principais, ele precisa saber construir sínteses, esquemas ou resumos dessa informação, bem como saber compará-la, criar novos conceitos, e identificar diferentes abordagens que os variados autores dão ao tema. De acordo com Brito Menezes (2006), a escola e o professor são os responsáveis por transformar o conteúdo científico em um conteúdo ensinável, processo chamado de transposição didática. A autora fala que essas transformações devem ser realizadas por meio de supressões, acréscimos e criações realizadas pelo professor.

A pergunta 11 analisa de forma mais detalhada o que 0 professor faz no processo de transformação da informação em saber a ser ensinado na sala de aula.

QUADRO 7 - Resultados da Questão 11.

\begin{tabular}{l|c}
\hline Ponto avaliado & Frequência \\
\hline $\begin{array}{l}\text { Mescla informações de diversos autores no intuito de adquirir uma } \\
\text { abordagem mais didática do tema. }\end{array}$ & 6 \\
\hline $\begin{array}{l}\text { Utiliza informações presentes nas fontes e acrescenta informações } \\
\text { suas ao tema. }\end{array}$ & 3 \\
\hline
\end{tabular}




\begin{tabular}{l|l}
\hline $\begin{array}{l}\text { Faz adaptações à linguagem, imagens e esquemas que seriam } \\
\text { apresentadas. }\end{array}$ & 4 \\
\hline $\begin{array}{l}\text { Articula estratégias e recursos que melhor se adaptam à } \\
\text { transmissão da informação do tema. }\end{array}$ & 6 \\
\hline Não acrescenta muita coisa às informações pesquisadas. & 0 \\
\hline $\begin{array}{l}\text { Geralmente, as informações pesquisadas não são suficientes para } \\
\text { construir minha aula. }\end{array}$ & 2 \\
\hline Outros & 0 \\
\hline
\end{tabular}

Seis entre sete professores afirmam que mesclam informações de diversos autores no intuito de adquirir uma abordagem mais didática do tema, caso que revela a preocupação do professor com um ensino de Química mais efetivo. A frequência também foi alta para o ponto "Articula estratégias e recursos que melhor se adaptam à transmissão da informação do tema", com seis professores respondentes. Esse processo de transformação feito pelo professor é chamado por Brito Menezes (2006) de Transposição Didática Externa, que consiste em trabalhar as informações pesquisadas nas fontes num saber a ensinar ao estudante. Esse processo é muito importante para a aprendizagem dos conceitos químicos, já que envolvem bastante abstração e visualização de fenômenos em nível microscópico. Os professores alegam também que realizam adaptações à linguagem, imagens ou esquemas que apresentam em suas aulas, com 4 marcações. Três professores disseram que utilizavam as informações das fontes, mas que também incorporavam informações suas, o que mostra que uma parte deles ainda não apreende à necessidade de fazer a transposição didática necessária para ensinar Química. E, por fim, dois professores assinalaram dificuldade em reconhecer e trabalhar com fontes suficientes para a construção da aula.

A décima segunda pergunta investiga quais produtos didáticos os professores mais utilizam como recursos de instrução nas aulas. Os resultados demonstrados foram:

QUADRO 8 - Resultados da Questão 11.

\begin{tabular}{l|c}
\hline Ponto avaliado & Frequência \\
\hline Trabalho de pesquisa & 3 \\
\hline Projeto visual (banners, cartazes, etc.) & 2 \\
\hline Softwares de apresentação (PPT, prezi, etc.) & 5 \\
\hline Quadro negro & 5 \\
\hline
\end{tabular}




\begin{tabular}{l|l}
\hline Dramatizações & 1 \\
\hline Jogos didáticos/RPG & 0 \\
\hline Mídias (CD, vídeos, simulações, hipermídias, etc.) & 5 \\
\hline Outros & 0 \\
\hline
\end{tabular}

A pesquisa revela que a maioria dos professores manejam as informações para usá-las no quadro negro e/ou Mídias $(C D$, vídeos, simulações, hipermídias, etc.) e/ou em Softwares de apresentação (com 5 marcações cada). É importante dizer que tais recursos de ensino da forma utilizados caracterizam maior concentração de falas sobre o professor. É dizer, o produto final para uso na aula ainda consiste em fortalecer o processo de transmissão-recepção que tem o professor como centro do processo de ensino-aprendizagem. Produtos como Trabalhos de Pesquisas (3), Dramatizações (1) ou Jogos didáticos/RPG (0) que favorecem maior participação dos estudantes em seu processo de aprendizagem são feitos com menos frequência pelos professores pesquisados.

Essa questão ainda solicitou uma justificativa do uso desses recursos pelos professores. As falas indicaram que os professores buscam utilizá-los da forma como a escola dispõe, pela sua facilidade de manuseio e pelo julgamento de ser mais eficiente no processo de aprendizagem dos alunos:

P2 e P4: "É o que dispomos".

P3: "Em busca de bons resultados".

P5: "Mais acessiveis e de fácil entendimento".

P7: "São os mais fáceis de levar para a sala de aula quando se tem

10 a 12 turmas para trabalhar; e principalmente quando se tem 20 a 25 aulas para preparar e ministrar por semana".

$\mathrm{Na}$ fala dos professores P1 e P6, já se identificam algumas falas diferentes no sentido de utilizar recursos que tentem se aproximar mais da realidade do estudante e permitam maior aprendizagem:

P1: "Acredito que esse conjunto de recursos pode auxiliar na veiculação das informações, pois alguns são do cotidiano dos alunos, isso faz com que a aula se aproxime do seu dia a dia"

P6: "Trazer inovação pedagógica das escolas de referências de Pernambuco."

A última pergunta avaliava o uso ético da informação pelos professores e as condições de compartilhamento de informações e 
proliferação científica:

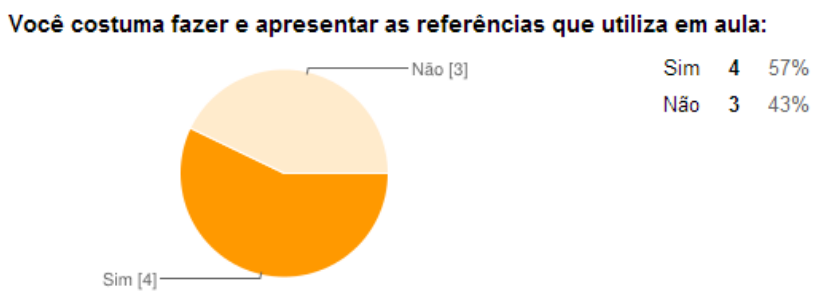

FIGURA 7 - Resultados da questão 12.

Embora a maioria dos professores atribua importância à apresentação das referências das fontes de informações consultadas em aula, outra parte considerável ainda não faz uso ético da informação consultada para seus estudantes. Para Libâneo (1994), o professor deve prover e indicar recursos que possibilitem a continuidade dos estudos dos estudantes sob sua tutela, meios que promovam a aprendizagem ativa. Para a ACRL (2000), o professor que não referencia suas fontes não faz uso ético da informação, pois impede que o conhecimento seja multiplicado e novamente acessado, e novamente reinterpretado e transformado. Quando os respondentes justificam a resposta da questão temos:

P1: "Acho importante que o aluno verifique por si que existe uma base científica sobre os assuntos vistos em sala."

P2: "não acho necessário".

P3: "Às vezes."

P4: "Pois não fui orientada para apresentar as referências."

P5: "Acho de extrema importância dar créditos a quem merece, é forma de reconhecimento ao trabalho de cada pessoa."

P6: "Assim torna mais confiável para o aluno."

P7: "Não é prática usual no ensino básico; ninguém pergunta que livro ou etc. você usou"

\section{CONSIDERAÇÕES FINAIS}

O contexto no qual o professor de Química está inserido necessita que ele detenha competências informacionais para atender às próprias demandas profissionais. Esta pesquisa apresenta algumas habilidades informacionais desses profissionais na cidade de Serra Talhada e as dificuldades que os cursos de formação de professores da cidade possuem para melhor preparar 
estes sujeitos.

Retomando os objetivos propostos, verificamos que as competências informacionais apresentadas dos professores de Química voltadas para as condições de estruturação das suas aulas demonstram avanços e conflitos, e que esse profissional ainda não apresenta competência informacional adequada para tratar do processso complexo que a atividade de ensino de Química exige.

No padrão 1 - "O indivíduo competente em informação determina a natureza e o nível de sua necessidade de informação" - os professores demonstraram dificuldades relevantes com relação ao estabelecimento de objetivos gerais e específicos da aula, já que não tiveram dificuldades em delimitar os conteúdos que utilizariam. Essa situação revela a necessidade de formação dos professores, não somente na própria Didática, visto que o trabalho docente precisa de bom delineamento e estabelecimento de metas educacionais. Demonstram que ainda há, nos sujeitos pesquisados, deficiência acerca da avaliação da necessidade de informação para as aulas e a avaliação prévia de como e quais conteúdos adequarse-ão a essa necessidade.

No padrão 2 - "O indivíduo competente em informação acessa a informação necessária eficaz e eficientemente" mostra que os professores de Química avaliados informam ter facilidade no acesso à informação. Entretanto, outras pesquisas devem ser avaliadas para julgar essa competência informacional, no sentido de saber se ela é superestimada e como ela se relaciona com as demais competências no desenvolvimento da aula de Química.

No padrão 3 - "O indivíduo competente em informação avalia a informação e suas fontes de forma crítica e incorpora a informação selecionada a seus conhecimentos básicos e a seu sistema de valores" - revela um professor de Química que informa saber selecionar a informação para aula, mas que tem dificuldades para organizá-la, reestruturá-la e aplicá-la em recursos didáticos. A competência informacional é importante nesse processo para ampliar o repertório, recursos e as ferramentas para que essas informações sejam estruturadas e aplicadas. O forte apego e confiança ao livro didático demonstrado pelos professores reforçam, também, a limitação deles em avaliar outras fontes de informações para integrar às suas aulas e recursos.

O quarto parâmetro " $O$ indivíduo competente em informação, individualmente ou na qualidade de membro de um 
grupo, utiliza a informação eficazmente para alcançar um propósito específico" - revela que o professor deve buscar formação para realizar a transposição didática. Os professores demonstraram dificuldades em elaborar estratégias de transformação da informação. Do ponto de vista da competência informacional, é possível dizer que o professor demonstra dificuldades em transformar aquelas informações das fontes em um outro tipo de produto que atenda às demandas específicas do ensino dos conteúdos de Química.

No padrão 5 "O indivíduo competente em informação compreende muitos problemas e questões econômicas, legais e sociais que rodeiam o uso da informação e acessa e utiliza a informação de forma ética e legal" - a maioria dos professores utiliza a informação com ética, mas uma parte considerável não referencia e/ou cita as fontes utilizadas nos seus produtos informacionais na aula.

A competência informacional dos professores desenvolve-se por meio do trabalho em conjunto das diferentes habilidades para o trato da informação, e essas habilidades não devem ser consideradas de forma isolada. Os resultados dessa pesquisa indicam que, de forma geral, a competência informacional do professor de Química de Serra Talhada necessita ser melhor trabalhada, e a relação entre muitas dessas habilidades não se dão de forma coerente e a falta de competência no trato da informação para as aulas acabarão dificultando o delineamento da proposta educativa das escolas em que esses sujeitos estarão inseridos. A busca pela excelência na transposição didática dos conteúdos pode tornar-se comprometida, consequentemente, na aprendizagem dos estudantes.

Acredita-se também que a elaboração dessa pesquisa baseada nos padrões propostos pela ACRL (2000) e os elementos de estruturação de uma aula (LIBÂNEO, 1994; CORDEIRO, 2007) auxiliou a compreender esse processo de busca, manejo, transformação e consumo da informação dentro do planejamento e execução da aula de Química. E agora impõe desafios para os cursos de formação no sentido de implementar e incentivar o trabalho com as competências informacionais em seus currículos e em atividades que mobilizem-nas para o trabalho nas práticas pedagógicas.

Compreendemos, também, como o estudo das competências informacionais é interdisciplinar ao Ensino de Química e à compreensão do trabalho de transposição didática do professor.

Esse estudo sugere muitos trabalhos e desafios no sentido 
de entender como as informações tão específicas da Química são trabalhadas no ato de ensinar e como são tratadas desde o processo de reconhecimento da necessidade de informação desse professor até a realização das aulas.

\section{REFERÊNCIAS}

AMERICAN LIBRARY ASSOCIATION. Presidential Committee on Information Literacy: Final report. 1989. Disponível em:

$<\mathrm{http}$ ://www.ala.org/acrl/publications/whitepapers/presidential>. Acesso em: 08 set. 2015. ACRL. Information Literacy competency for higher education. Chicago: ALA, 2000. Disponível em: <http://www.ala.org/acrl/ilcomstan.html > Acesso em: 06 de maio de 2014 BOUGNOUX, D. Introdução às ciências da informação e da comunicação. Petrópolis: Vozes, 1994. 336p.

BRITO MENEZES, A. P. O Contrato Didático e Transposição Didática: Inter-relações entre fenômenos Didáticos na iniciação à álgebra na $6^{a}$ série do Ensino Fundamental. Tese de Doutorado. Doutorado em Educação UFPe, 2006.

CAMPELLO, B. O movimento da competência informacional: uma perspectiva para o letramento informacional. Ci. Inf, Brasília, v. 32, n. 3, p. 28-37, set. 2003.

$\mathrm{CHOO}, \mathrm{C}$. W. Como ficamos sabendo - um modelo de uso da informação. In: A organização do conhecimento. São Paulo: SENAC, 2003.

DUDZIAK, E. A. A Information literacy e o papel educacional das bibliotecas. 2001. 173 p. Dissertação (Mestrado em Ciências da Comunicação) - Escola de Comunicações e Artes da Universidade de São Paulo, São Paulo, 2001.

FEDERAÇÃO INTERNACIONAL DE ASSOCIAÇÕES DE BIBLIOTECÁRIOS E BIBLIOTECAS. Manifesto da IFLA sobre a internet, 2002. Disponível em:

$<$ http://www.ifla.org/files/assets/faife/publications/policy-documents/internetmanifesto-pt.pdf>. Acesso em: 01 de maio de 2014.

GASQUE, K. C. G. D. Letramento Informacional: pesquisa, reflexão e aprendizagem. Brasília: Faculdade de Ciência da Informação / Universidade de Brasília, 2012. 175 p.

KUHLTHAU, C. C.Literacy and learning for the information age.

In:STRIPLING, B. K. Learning and libraries in an information age.

Englewood: Libraries Unlimited, 1999. p. 3-21.

LÉVY, P. As tecnologias da inteligência: o futuro do pensamento na era da informática. Rio de Janeiro: Ed. 34, 1993. 208p.

LIBÂNEO, C. Didática. São Paulo: Cortez, 1994. 
MATA, M. L. A competência informacional de graduandos de biblioteconomia da região sudeste: um enfoque nos processos de busca e uso ético da informação. 2009. 162 f. Dissertação (Mestrado) Curso de Mestrado em Ciência da Informação, Universidade Estadual Paulista, Marília, 2009.

NEVES, J. L. Pesquisa Qualitativa: característica, usos e possibilidades. Caderno de Pesquisas em Administração, São Paulo, v. 1, n. 3, jun. 1996. Disponível em: <http://www.ead.fea.usp.br/cad-pesq/arquivos/C03art06.pdf>. Acesso em: $18 \mathrm{dez} .2008$.

NUÑÉZ, I. B.; RAMALHO, B. L.; SILVA, K. P e CAMPOS, A. P. A. A seleção dos livros didáticos: um saber necessário ao professor. O caso do Ensino de Ciências. Organización de Estados Iberoamericanos para la Educación, la Ciência y la Cultura (OEI). Disponível em:

<www.rieoei.org/deloslectores/427Beltran.pdf>. Acesso em: 14 maio 2014.

SANTOS, T. F.. Competência informacional no ensino superior: um estudo de discentes de graduação em Biblioteconomia no Estado de Goiás. 2011. 148 f. Tese (Doutorado) - Curso de Mestrado em Ciência da Informação, Unb, Brasília, 2011.

SULLIVAN, Katy. Developing a topic and identifying sources of information. In: NEELY, T. Y. Information Literacy Assessment: standards-based tools and assignments. Chicago: American Library Association, 2006. p. 19-43 